\title{
Determination of Arsenic by High Power Nitrogen Microwave Induced Plasma Atomic Emission Spectrometry with Hydride Generation Technique
}

\author{
Taketoshi NAKaHARA and Nobuaki TAKeUCHI \\ Department of Applied Chemistry, Osaka Prefecture University, Sakai, Osaka 599, Japan
}

\begin{abstract}
High power nitrogen microwave induced plasma was used as a new excitation source for atomic emission spectrometry to determine low concentrations of arsenic in combination with hydride generation technique. Under the optimized experimental conditions, the best attainable detection limits at As(I)188.979 nm was $3.13 \mathrm{ngAs} / \mathrm{ml}$ with a linear dynamic range of 10 to $5000 \mathrm{ngAs} / \mathrm{ml}$. The presence of several diverse elements has been found to cause more or less a depressing interference with the determination of arsenic by the present technique. The present method was applied to the determination of total arsenic in the samples of sea weed and scallop to be issued as standard reference materials by National Institute for Environmental Studies, Japan. The samples were dissolved in a mixture of nitric and sulfuric acids with the addition of hydrofluoric acid. The results obtained by this method were very reproducible and satisfactory.
\end{abstract}

Keywords High power nitrogen microwave induced plasma, atomic emission spectrometry, hydride generation technique, arsenic, sea weed, scallop.

Microwave induced plasma (MIP) has become a powerful source of excitation and ionization, enabling not only the determination of metals but also of many nonmetals. However, such MIPs as ones produced by either the Beenakker cavity ${ }^{2-7}$ or the Surfatron ${ }^{8-10}$, are subject to a number of serious limitations. Most importantly, these MIPs have a low tolerance to liquid aerosol. Furthermore, it was impossible to produce an annular-shaped (toroidal) plasma similar to that of the inductively coupled plasma (ICP). On the other hand, the argon ICPs have been widely used for trace element analysis using mass spectrometry (MS) as well as atomic emission spectrometry (AES). In general, both Ar ICP-AES and Ar ICP-MS have found widespread use in a number of practical fields, because they give high sensitivity and good precision in trace element analysis. ${ }^{11-14}$ In particular, however, in Ar ICP-MS, ${ }^{39} \mathrm{~K}^{+}$, ${ }^{40} \mathrm{Ca}^{+},{ }^{52} \mathrm{Cr}^{+},{ }^{36} \mathrm{Fe}^{+}$and ${ }^{80} \mathrm{Se}^{+}$cannot be determined directly by Ar ICP-MS, because the determination of these elements suffer interferences from ${ }^{38} \mathrm{ArH}^{+},{ }^{40} \mathrm{Ar}^{+},{ }^{40} \mathrm{ArC}^{+}$, ${ }^{40} \mathrm{ArO}^{+}$and ${ }^{40} \mathrm{Ar}_{2}^{+}$, respectively, which are caused by the plasma sustained gas of the Ar ICP. In order to overcome these limitations, recently, Okamoto ${ }^{15.16}$ developed and described an annular-shaped high power nitrogen MIP at atmospheric pressure, especially for MS, the system of which has been commercially available.

The high power nitrogen microwave induced plasma $\left(\mathrm{N}_{2}\right.$ MIP) is more robust than the Ar ICP; for example, the plasma is not extinguished even if an air sample is injected and also a hydride generation technique to be mentioned below is combined in the continuous mode. Surprisingly, only some emission characteristics of this high power $\mathrm{N}_{2}$ MIP for AES have been investigated to date. ${ }^{15,17}$ To the knowledge, no paper has been published on the application of the high power $\mathrm{N}_{2}$ MIP for AES in the practical analysis. This paper describes the feasibility of the high power $\mathrm{N}_{2}$ MIP for AES for the determination of arsenic in combination with both conventional solution nebulization and hydride generation technique. The results obtained by both sample introduction methods are compared in terms of analytical figures of merit for arsenic. Finally, the present method coupled with hydride generation technique has been successfully applied to the determination of total concentrations of arsenic in samples of sea weed and scallop.

\section{Experimental}

\section{Instrumentation and apparatus}

A schematic diagram of the experimental apparatus is shown in Fig. 1. The microwave excitation source (high power $\mathrm{N}_{2}$ MIP) is essentially the same as described previously. ${ }^{\text {is }}$ Microwave power is transferred from a magnetron $(2.45 \mathrm{GHz}, 1 \mathrm{~kW})$ of a Nippon Koushuha MKN-103-3S microwave power generator to the discharge tube (torch) through a uniline, directional coupler, three-stub tuner, tapered waveguide, and an Okamoto cavity (Hitachi), the details of which are already described in the literature. ${ }^{15-17} \mathrm{~A}$ high power $\mathrm{N}_{2}$ MIP source together with a magnetron was mounted on a laboratory-made optical rail for $x-y-z$ direction adjustments. An annular-shaped 


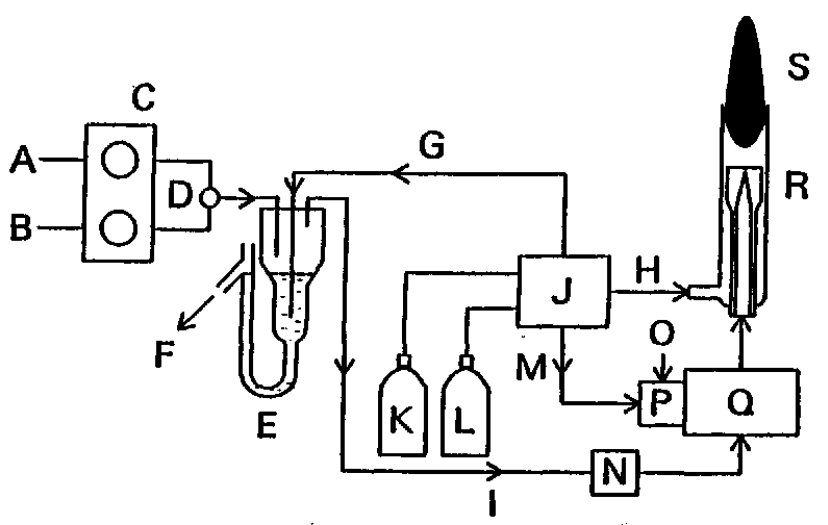

Fig. 1 Schematic diagram of high power $\mathrm{N}_{2}$ MIP-AES system coupled with hydride generation technique. A, sample solution for hydride generation; $B$, reductant solution; $C$, peristaltic pump; D, mixing joint; $E$, gas-liquid separator; F, waste; G, carrier gas; H, plasma gas; $\mathbf{I}$, carrier gas and hydride; J, gas controller; $K$, nitrogen tank; $L$, argon tank; $M$, nebulizer gas; $N$, drying flask; $O$, sample solution for nebulization; $P$, nebulizer; $Q$, nebulizer chamber; $R$, plasma torch; S, MIP.

(toroidal) plasma is formed above the quartz torch. The computer-controlled sequential spectrometer used in this work was a part of a Nippon Jerrell-Ash ICAP-575 II inductively coupled plasma emission spectrometer. The plasma was viewed side-on through a quartz lens (focal length $200 \mathrm{~mm}, 1: 1$ image) and focused on the entrance slit of the spectrometer. In this work, the wavelengths and photomultiplier voltage used for arsenic atomic emission measurements were As(I) 188.979 and $193.696 \mathrm{~nm}$ and $-1000 \mathrm{~V}$, respectively. The sample introduction systems included a conventional pneumatic nebulization of solutions and a hydride generation technique. For hydride generation, a laboratory-made gas-liquid separator (Fig. 1) fabricated from borosilicate glass was used and has been described in a previous paper. ${ }^{18}$ In addition, a drying flask filled with sulfuric acid was installed between a gas-liquid separator and a nebulizer chamber to remove the water vapor produced during hydride generation.

\section{Reagents}

Stock solutions (1.000 mg/ml) of As(III) and As(V) were prepared from high-purity arsenic(III) oxide and analyticalreagent grade disodium hydrogen arsenate $\left(\mathrm{Na}_{2} \mathrm{HAsO}\right)_{4}$, respectively, and standandized by conventional ICP-AES with solution nebulization. Solutions of lower concentration were prepaned by appropriate dilution of the stock solutions immediately before use. Solutions of As(III) was used, unless otherwise stated. Laboratory-reagent grade sodium tetrahydroborate $\left(\mathrm{NaBH}_{4}\right)$ was used to prepare a stabilized tetrahydroborate solution, in sodium hydroxide to decrease its rate of decomposition, which could be pumped without out-gassing and could be used for several days. All other reagents and solutions used were either of analyticalreagent grade or the highest purity available. High-purity water (Milli-Q water) was obtained by passing distilled water through a Milli-Q ion-exchange and membranefiltering system (Millipore).

\section{General procedure}

An acidified sample solution and the alkaline tetrahydroborate solution are continuously introduced into the hydride generator with the aid of a peristaltic pump and Tygon tubing. The generated arsenic hydride ("arsine") along with excess hydrogen is continuously fed into the high power $\mathrm{N}_{2}$ MIP source by nitrogen carrier gas through the drain outlet of the conventional nebulizer chamber. In this manner, it is possible easily to interchange the analytical method between that using the conventional pneumatic nebulizer and that employing the hydride generator. All emission intensities, when stabilized, are integrated, at least in triplicate, over a fixed period of $3 \mathrm{~s}$. Background emission (including emission from the reagent blank) integrated over the same period, is subtracted from all line emission data to obtain the net line emission intensities.

\section{Sample digestion procedure}

The samples of sea weed and scallop were provided by National Institute for Environmental Studies, Japan. These samples were distributed to many organizations, including universities, governmental institutes and private companies, for the collaborative analysis. The procedure for the sample preparation is described as follows. With the use of Teflon beakers, $0.5-g$ portions of the samples were digested in $6 \mathrm{ml}$ of a mixture of nitric and sulfuric acids (1:1 by volume) with $2-3 \mathrm{ml}$ of $1.0 \%$ (w/v) potassium permanganate solution as an oxidative catalyst described by Hahn $e t$ $a^{19}{ }^{19}$ and $5-10 \mathrm{ml}$ of hydrofluoric acid with heating on a hot plate. After cooling, $15 \mathrm{ml}$ of Milli-Q water and $5 \mathrm{ml}$ of hydrochloric acid were added to the resultant solutions. These solutions were gently heated on a hot plate, cooled and transferred to $200-\mathrm{ml}$ volumetric flasks. After the addition of $2.0 \mathrm{~g}$ of potassium iodide to pre-reduce the As(V) to As(III), the sample solutions were diluted to volume with hydrochloric acid and Milli-Q water to give a final acidity of $1.0 \mathrm{M}$ in hydrochloric acid.

\section{Results and Discussion}

\section{Optimization of experimental parameters}

In an attempt to obtain a maximum line-to-background intensity ratio for arsenic, various operating parameters were studied and optimized individually while the other parameters were kept at their optimum values. The parameters investigated were microwave power to the plasma, analytical wavelength, observation position, nitrogen flow rates of plasma and carrier gases for both sample introduction methods of solution nebulization and hydride generation. In addition, the effect of concentration of tetrahydroborate solution and of acidity and flow rate of sample solution was examined for hydride generation. Table 1 shows the optimized operating conditions used for arsenic emission intensity measurements. It should be stressed here that under the operating conditions shown in 
Table 1 there is no possibility of extinguishing of this high power $\mathrm{N}_{2}$ MIP by excess hydrogen produced during hydride generation at all, in contrast with conventional Ar ICP.

Table 1 Optimized operating conditions for the determination of arsenic

\begin{tabular}{lcc}
\hline & $\begin{array}{c}\text { Solution } \\
\text { nebulization }\end{array}$ & $\begin{array}{c}\text { Hydride } \\
\text { generation }\end{array}$ \\
\hline Microwave power & $1000 \mathrm{~W}$ & $1000 \mathrm{~W}$ \\
Plasma gas flow rate & $15.0 \mathrm{1} / \mathrm{min}$ & $15.0 \mathrm{1} / \mathrm{min}$ \\
Carrier gas flow rate & $0.6 \mathrm{1} / \mathrm{min}$ & $0.51 / \mathrm{min}$ \\
Wavelengths & $188.979 \mathrm{and}$ & $188.979 \mathrm{and}$ \\
& $193.696 \mathrm{~nm}$ & $193.696 \mathrm{~nm}$ \\
Sample solution flow rate & & $10.9 \mathrm{ml} / \mathrm{min}$ \\
Sample acidity & & $1.0 \mathrm{M} \mathrm{in} \mathrm{HCl}$ \\
NaBH & & $9.9 \mathrm{ml} / \mathrm{min}$ \\
NaBH & & \\
NaOH concentration & & $0.7 \%(\mathrm{w} / \mathrm{v})$ \\
Reaction tube length & & $0.1 \mathrm{M}$ \\
& & $10.0 \mathrm{~cm}$ \\
\hline
\end{tabular}

\section{Analytical working graphs and detection limits}

Under the optimized operating conditions depicted in Table 1, double logarithmic analytical working graphs were obtained for arsenic at 188.979 and $193.696 \mathrm{~nm}$ with use of freshly prepared arsenic(III) solutions by both a conventional solution nebulization and a hydride generation technique. Some analytical figures of merit for arsenic obtained from the analytical working graphs(not shown here) are depicted in Table 2. Detection limits for arsenic were extrapolated from the linear calibration graphs and were defined as the concentration of the analyte that would produce a net signal (i.e., background-corrected line intensity) equal to three times the standard deviation of the background emission intensity, in acoondance with IUPAC recommendation. These detection limits obtained by the present hydride generation-high power $\mathrm{N}_{2}$ MIP-AES are somewhat poorer than those obtained by ICP-AES coupled with hydride generation. ${ }^{20-23}$ The more sensitive As(I) 188.979nm line was selected as an analytical line and used throughout in the following study.

\section{Pre-reduction step}

It is well known that the arsenic may be present in practical samples in two typical oxidation states, +3 and +5 , which exhibit pronounced differences in their analytical behavior. ${ }^{26}$ Most determinations of the total arsenic, therefore, call for a pre-reduction step of arsenate, $\mathrm{As}(\mathrm{V})$, to arsenite, As(III), prior to hydride generation. In this work, the effects of various concentrations of potassium iodide, the most typical pre-reductant ${ }^{20.23}$, in the $1.0 \mathrm{M}$ hydrochloric acid on arsine generation from As(III) and As(V) were investigated in terms of the emission intensity for As(III) and As(V) and their ratio. As a consequence, the efficiency of arsine generation from $\mathrm{As}(\mathrm{V})$, as expected, was much lower than that from As(III), but in the presence of potassium iodide at concentrations above $1.0 \%(\mathrm{w} / \mathrm{v})$, both oxidation states have the same emission intensity. The final concentration of potassium iodide in the acidified sample solutions, therefore, was adjusted to $1.0 \%(w / v)$ for the determination of total arsenic in the samples.

\section{Effect of diverse elements}

The determination of arsenic by hydride generationatomic spectrometry is well known to be susceptible to interferences from various diverse elements. ${ }^{20-23}$ Under the experimental conditions used here, the effect of various other elements on the arsenic determination was examined. The results of depressing interferences from some elements are shown in Table 3. Interference is considered to have occurred when an emission intensity is changed by over $\pm 10 \%$ from that for arsenic alone. The following elements (ions) at levels a 1000-fold greater than arsenic(III) did not interfere: $\mathrm{Al}, \mathrm{B}, \mathrm{Bi}, \mathrm{Cd}, \mathrm{Ce}, \mathrm{Cr}$ (III), Cs, Ga, Ge, $\mathrm{Hg}, \mathrm{In}, \mathrm{K}, \mathrm{La}, \mathrm{Li}, \mathrm{Mg}, \mathrm{Mn}, \mathrm{Mo}, \mathrm{Na}, \mathrm{P}, \mathrm{Pb}, \mathrm{Rb}, \mathrm{Sb}, \mathrm{Si}$, $\mathrm{Sr}, \mathrm{Ti}, \mathrm{Ti}, \mathrm{Y}, \mathrm{Zn}, \mathrm{Zr}, \mathrm{Br}, \mathrm{Cr}, \mathrm{CN}, \mathrm{Co}_{3}^{2}, \mathrm{C}_{2} \mathrm{O}_{4}^{2}, \mathrm{~F}$, $\mathrm{HCO}_{3}{ }^{-}, \mathrm{NH}_{4}^{+}, \mathrm{SO}_{3}^{2}, \mathrm{SO}_{4}^{2-}$ and $\mathrm{SCN}$.

\section{Application to the determination of total arsenic in the} samples of sea weed and scallop

On the basis of the observations described above, the present hydride generation-high power $\mathrm{N}_{2}$ MIP-AES was applied to the determination of total arsenic in the samples of sea weed and scallop. The presence of some elements in the samples would be expected to cause low results in the determination of arsenic. A recovery study was carried out by adding known amounts of arsenic(III) to the acidified sample solutions together with $1 \%(w / v)$ potassium iodide and applying the operating conditions given in Table 1.

Table 2 Analytical figures of merit for arsenic obtained by conventional solution nebulization and hydride generation with high power $\mathrm{N}_{2}$ microwave induced plasma atomic emission spectrometry

\begin{tabular}{|c|c|c|c|c|c|c|}
\hline \multirow{2}{*}{$\begin{array}{l}\text { Wavelength/ } \\
\text { nm }\end{array}$} & \multicolumn{3}{|c|}{ Solution nebulization } & \multicolumn{3}{|c|}{ Hydride generation } \\
\hline & $\begin{array}{c}\text { Dynamic range/ } \\
\mu \mathrm{g} \mathrm{ml}^{-1}\end{array}$ & $\begin{array}{c}\text { Detection } \\
\operatorname{limit} / \mu \mathrm{g} \mathrm{ml}^{-1}\end{array}$ & $\begin{array}{l}\text { Correlation } \\
\text { coefficient (r) }\end{array}$ & $\begin{array}{c}\text { Dynamic range/ } \\
\mathrm{ng} \mathrm{ml}^{-1}\end{array}$ & $\begin{array}{c}\text { Detection } \\
\text { limit/ngml } \mathbf{m}^{-1}\end{array}$ & $\begin{array}{l}\text { Correlation } \\
\text { coefficient }(r)\end{array}$ \\
\hline As(I)188.979 & $2 \sim 1 \times 10^{3}$ & 0.75 & 0.999 & $10 \sim 5 \times 10^{3}$ & 3.13 & 0.998 \\
\hline As(I)193.696 & $2 \sim 1 \times 10^{3}$ & 1.43 & 0.998 & $10 \sim 5 \times 10^{3}$ & 5.56 & 0.997 \\
\hline
\end{tabular}


Table 3 Effect of diverse elements (ions) on arsenic intensity by hydride generation-high power $\mathrm{N}_{2}$ MIP-AES

\begin{tabular}{|c|c|c|c|}
\hline $\begin{array}{l}\text { Element } \\
\text { (ion) }\end{array}$ & Added as & $\begin{array}{l}\text { Amount added } / \\
\qquad \mu \mathrm{g} \mathrm{ml}^{-1}\end{array}$ & $\begin{array}{l}\text { Relative } \\
\text { intensity }\end{array}$ \\
\hline Ag & $\mathrm{AgNO}_{3}$ & 20 & 100 \\
\hline Au & $\mathrm{HAuCl}_{4} \cdot 4 \mathrm{H}_{2} \mathrm{O}$ & 0.2 & 43 \\
\hline Co & Metal in $\mathrm{HCl}$ & 0.2 & 95 \\
\hline $\operatorname{Cr}(\mathrm{VI})$ & $\mathrm{K}_{2} \mathrm{Cr}_{2} \mathrm{O}_{4}$ & 0.2 & 30 \\
\hline $\mathrm{Cu}$ & $\mathrm{CuSO}_{4} \cdot 5 \mathrm{H}_{2} \mathrm{O}$ & 0.2 & 100 \\
\hline $\mathrm{Fe}$ & $\mathrm{FeCl}_{2} \cdot 6 \mathrm{H}_{2} \mathrm{O}$ & 0.2 & 80 \\
\hline $\mathbf{N i}$ & $\mathrm{NiCl}_{2} \cdot 4 \mathrm{H}_{2} \mathrm{O}$ & 0.2 & 94 \\
\hline Pd & $\mathrm{PdCl}_{2}$ & 0.2 & 3 \\
\hline $\mathbf{P t}$ & $\mathrm{H}_{2} \mathrm{PtCl}_{6}$ & 0.2 & 71 \\
\hline Se & $\mathrm{Na}_{2} \mathrm{SeO}_{3}$ & 20 & 101 \\
\hline Sn & Metal in $\mathrm{HCl}$ & 20 & 105 \\
\hline $\mathrm{Te}$ & $\mathrm{Na}_{2} \mathrm{TeO}_{3}$ & 0.2 & 92 \\
\hline $\mathbf{V}$ & $\mathrm{NH}_{4} \mathrm{VO}_{3}$ & 20 & 102 \\
\hline $\mathbf{w}$ & $\mathrm{Na}_{2} \mathrm{WO}_{4} \cdot 2 \mathrm{H}_{2} \mathrm{O}$ & 2 & 101 \\
\hline $\mathrm{BrO}_{3}^{-}$ & $\mathrm{KBrO}_{3}$ & 0.2 & 46 \\
\hline $\mathrm{ClO}_{3}^{-}$ & $\mathrm{NaClO}_{3}$ & 0.2 & 49 \\
\hline $\mathrm{H}_{3}^{+}$ & $\mathrm{KIO}_{3}$ & 0.2 & 41 \\
\hline $\mathrm{NO}_{2}^{-}$ & $\mathrm{NaNO}_{2}$ & 2 & 101 \\
\hline $\mathrm{NO}_{3}$ & $\mathrm{KNO}^{\circ}$ & 20 & 101 \\
\hline $\mathbf{S}^{2-}$ & $\mathrm{Na}_{2} \mathbf{S}$ & 2 & 98 \\
\hline
\end{tabular}

a. Relative to $\mathbf{1 0 0}$ for the emission intensity of arsenic $\mathbf{( 0 . 2}$ $\mu \mathrm{g} / \mathrm{ml}$ ) alone.

The added arsenic was recovered in the range $96-100 \%$, depending on the samples. Therefore, a calibration graph method could be employed in the arsenic determination. The results for several samples of sea weed ("hijiki") and scallop, shown in Table 4, were calculated by least-squares analysis, and show good precision. The samples used here were distributed to many organizations and will be issued as standard reference materials by National Institute for Environmental Studies, Japan for the collaborative study of the determination of total arsenic. However, the accuracy of these results obtained in this study can't be known at the present time as this collaborative work has not yet been finished to date.

In conclusion, the method described has proved to be a useful and rapid approach to improving the sensitivity of

Table 4 Determination of total arsenic in samples of sea weed ("hijiki") and scallop by the proposed technique

\begin{tabular}{lcc}
\hline Sample & $\begin{array}{c}\text { Water content/ } \\
\%\end{array}$ & $\begin{array}{c}\text { Total arsenic } \\
\mu \text { g/g-dry weight }\end{array}$ \\
\hline Hijiki-1 & 5.4 & $51.2 \pm 1.9$ \\
Hijiki-2 & 4.9 & $53.1 \pm 1.8$ \\
Scallop & 2.8 & $7.6 \pm 0.4$ \\
\hline
\end{tabular}

a. The mean \pm standard deviation $(n=10)$. arsenic determination. The sensitivity and precision of the method reported here are adequate for he determination of trace concentrations of arsenic in the samples of sea weed and scallop.

This work was supported in part by a Grant-in-Aid for Scientific Research (No. 07455334) from the Ministry of Education, Science, Sports and Culture of Japan.

\section{References}

1. R. D. Satzger, J. Microwave Power Electromag. Energy, 24, 132 (1989).

2. C. I. M. Beenakker, Spectrochim. Acta, 31 B, 483 (1976).

3. R. D. Deutsch and G. M. Hieftje, Appl. Spectrosc., 39, 214 (1985).

4. D. L. Haas and J. D. Jamerson, Spectrochim. Acta, 42B, 299 (1987).

5. J. J. Urh and J. W. Carnahan, Appl. Spectrosc., 40, 877 (1986).

6. R. D. Satzger, F. L. Fricke and J. A. Caruso, J. Anal. At. Spectrom., 3, 319 (1988).

7. J. T. Creed, T. M. Davidson, W.-L. Shen, P. G. Brown and J. A. Caruso, Spectrochim. Acta, 44B, 909 (1989).

8. J. Hubert, M. Moisan and A. Ricard, Spectrochim. Acta, 33B, 1 (1979).

9. P. S. Moussounda, P. Ranson and J. M. Mermet, Spectrochim. Acta, 40B, 641 (1985).

10. M. Selby, R. Rezaaiyaan and G. M. Hieftje, Appl. Spectrosc., 41, 749 (1987).

11. P. W. J. M. Boumans, "Inductively Coupled Plasma Emission Spectroscopy", Parts I and II, Wiley, New York, 1987.

12. A. Montaser and D. W. Golightly, "Inductively Coupled Plasma in Analytical Atomic Spectrometry", 2nd. edn., VCH, New York, 1992.

13. K. E. Jarvis, A. L. Gray and R. S. Houk, "Handbook of Inductively Coupled Plasma Mass Spectrometry", Blackie, London, 1992.

14. G. Holland and A. N. Eaton, "Application of Plasma Source Mass Spectrometry II", Royal Society of Chemistry, Cambridge, 1993.

15. Y. Okamoto, Anal. Sci., 7, 283 (1991).

16. Y. Okamoto, J. Anal. At. Spectrom., 9, 745 (1994).

17. M. Ohata and N. Furuta, J. Anal. At. Spectrom., 12,341 (1997).

18. T. Nakahara and T. Mori, J. Anal. At. Spectrom., 9, 159 (1994).

19. M. H. Hahn, K. A. Wolnik, F. L. Fricke and J. A. Caruso, Anal. Chem., 54, 1048 (1982).

20. T. Nakahara, Anal. Chim. Acta, 131, 73 (1981).

21. J. D. Hwang, G. D. Guenther and J. P. Diomiguardi, Anal. Chem., 61, 285 (1989).

22. P. Schramel and L.-Q. Xu, Fresenius J. Anal. Chem., 340, 41 (1991).

23. T. Nakahara, in "Advances in Atomic Spectroscopy", Vol. 2, ed. J. Sneddon, pp. 139-178, JAI Press, Greenwich (U.S.A.), 1995. 